Human Journals

Research Article

July 2020 Vol.:16, Issue: 1

(C) All rights are reserved by VAILSON BATISTA DE FREITAS et al.

\title{
Understanding as a Form of Cooperation and Motivation in an Intra-Organizational Network
}

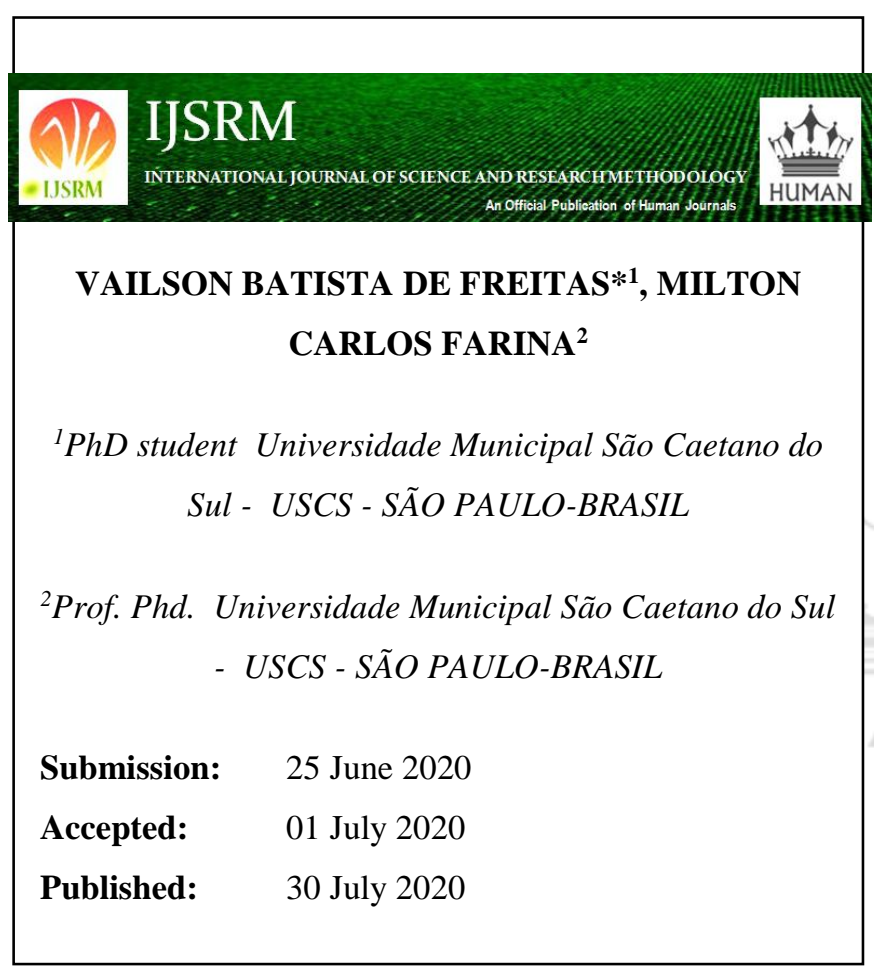
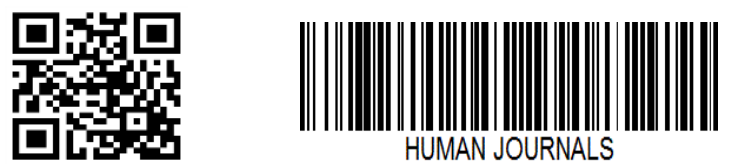

www.ijsrm.humanjournals.com
Keywords: Social Networks; Centrality Measures; IntraOrganisational Knowledge; Tacit Knowledge; Behaviour; Institutional Policy; Collaboration; Organizational Communication

\section{ABSTRACT}

Background: This study starts with the assumption that institutions need to know their networks by mapping their configurations, seeking efficiency in processing information, and generating knowledge and innovation to provide a superior structuring for learning. Aim: The objective of this research is to analyse the relationship network among the employees of a large national bank branch to understand each employee's perspective on the importance of the work performed by colleagues in the day-to-day operations of the branch. Setting: The study is carried out in a quantitative descriptive way, defining the participants of a social network and their possible relationships, considering that descriptive research makes it possible to describe the events of a given group. According to Gil (2010), this form of research facilitates descriptions of the attributes of individuals, organisations, and populations, with the employees of a bank branch of a large Brazilian state bank. Methods: The research is carried out using descriptive quantitative methods to define the participants in a social network and their possible relationships. Results: The study found that, within the group, employees who have held certain positions or functions longer have a greater understanding of other activities, as do those who occupy higher positions in the hierarchy. Such employees are involved with all other activities on a larger or smaller scale and, thus, have a greater understanding of these activities. Conclusions: The results allow us to conclude that, for the group studied, there is a certain degree of interaction for which most of the actors understand the activities performed by their colleagues. Thus, we can conclude that this understanding leads to the creation of ties that help in the learning of new activities and finding eventual solutions to problems that arise in the execution of daily activities. 


\section{INTRODUCTION}

This study aims to understand how interorganisational networks work. In other words, it investigates how such networks can facilitate the understanding of the process of activities in organisations and map the information identified in secondary areas (support) to develop tasks for employees to perform.

This research utilises a survey of the employees of a branch of a national bank regarding their understanding of the daily activities performed by their colleagues and whether this understanding influences their interpersonal relationships.

We begin with the assumption that institutions need to understand their networks by mapping their configuration, seeking efficiency in processing information, and generating knowledge and innovation to provide a better structure for learning.

Issues related to the creation, propagation, displacement, and archiving of knowledge have become the focus of discussions in the organisational literature on knowledge management. Nonaka and Takeuchi (2008) introduce the subject of knowledge conversion, pointing out that it is generated and disseminated through social media.

The dissemination of knowledge is the agent of creation, quality, and renewal of knowledge. Thus, it is important to identify the levels of relationships in an inter- or intra-organisational social network and understand how the establishment of the network can be used to support knowledge management, considering that people interact and exchange information and understand how their knowledge of their colleagues is important to solve the problems and work-related issues that arise in everyday life.

The study focuses on knowledge management and Social Network Analysis (SNA) to provide an understanding of how network participants relate to their colleagues in the search for information to perform their daily activities and find solutions to occasional problems at the branch; how they interact and cooperate with each other to promote the generation of knowledge, in which they play a major role; and how each employee determines whether the work of each colleague is important to the development of the bank branch's activities. 
The objective of this research is to analyse the relationship network among the employees of a large national bank branch to understand how each employee views the importance of the work performed by their colleagues in the day-to-day operations of the branch. We identify which employees have a better understanding of the knowledge and skills of their colleagues and how this understanding influences the communication among team members.

The topic is considered relevant because interpersonal relations, especially those regarding knowledge transfers and solutions to occasional work problems, have become increasingly important for institutions seeking to develop employee qualification and training plans.

It is expected that by taking this approach to this topic, this study can lead to complementary studies on this subject because the results are expected to be relevant in academia, business, and the public sector.

\section{1- THEORETICAL REVIEW}

In the theoretical review, the concept of social networks is treated according to the perspectives of researchers on collaborative networks, measures of centrality, and tacit and explicit knowledge.

\section{1 - SOCIAL NETWORKS}

Networks are systems comprised of 'nodes' and the connections between them. In the social sciences, they are made up of social actors (e.g. individuals, groups, organisations, etc.) connected by some kind of relationship. Generally, these actors can be studied to understand how they behave and how the connections influence this behaviour, with applications to public health, information technology, sociology, economics, and applied mathematics (Watts 1999).

Some studies that serve as basis for these categories are found in the SNA literature, such as studies addressing the concept of network centrality proposed by Freeman (1979). According to Freeman (1979), the centrality of a network can be divided into three basic categories: a) degree centrality (measured by the number of links that an actor has with other actors in the network), b) closeness centrality (based on the proximity or distance of an actor to other 
actors in a network), and c) betweenness centrality (referring to the intermediate links that connect other actors who are not directly connected).

Brazil (Marteleto 2001; Pinto \& Junqueira 2009; Rossoni, Hocayen-Da-Silva \& Ferreira Jr. 2009). Freeman's (1979) concept of centrality has become the focus of many international studies (Everett \& Borgatti 2005; Hanneman 2001; Hanneman \& Riddle 2005; Scott 2000; Wasserman \& Faust 1994) as well as studies focused on.

One way to carry out studies in applied social sciences is to analyse social networks to understand the relationships between the various actors that compose them (Farina 2014). This process, referred to as SNA, focuses on the study of small groups in the sociometry of relationships between people, as is verified by Harvard researchers, and the relationships between groups, as are observed by anthropologists in Manchester (Scott 2000).

SNA has been increasingly used in studies of social phenomena as an alternative to atomistic and subject-centred approaches. Unlike in Anglo-Saxon academic world, however, this approach is not yet widespread in Brazil. This approach focuses on social relationships, reflecting the perception of inseparability between economic actions and the search for approval, status, socialisation, and power (Marques 2006).

Marques (2006) also considers that social networks structure various dimensions of society and that the relationships and positions in these networks constitute organisational structures that determine choices, providing differentiated access to goods and instruments of power. This access makes certain alliances and conflicts more or less possible, influencing the results of institutional policies.

The universe of social networks generates connections between their members through the creation of common goals and coexistence in the same (geographical) environment. The use of social networks can be related to resource acquisition in addition to providing an opportunity to connect new participants and, thus, share goals with them (Silva et al. 2006).

To understand social networks, it is necessary to study their various relational possibilities, that is, the relationships practiced between the members of a network. Thus, studies that focus on social networks consider groups of companies and people to understand their actions 
and movements, such as commercial operations between the participants that form the network and generate links between them (Wasserman \& Faust 1994).

For Ahuja (2000), these links can be understood as cooperative actions between the organisations that generate knowledge and skills (know-how) to be divided among the participants. Through databases, information technology has made the growth of studies related to SNA possible (Silva et al.2006).

Nelson (1984) explains that social networks can be seen as groups of links between participants. These links can be formal or informal, weak or strong, and occurring sporadically or frequently.

For Castells (1999, p. 498), social networks are like a set of interconnected nodes that allow communication between the elements that comprise the network, providing a social relationship between the actors that participate in the network.

Social networks constitute the invisible structure of the social fabric (Latour 2011). SNA is an interdisciplinary approach for dynamically reading social interactions with a specialised vocabulary that expresses the complexity of the different dimensions of social relations.

The concept of networks can be seen from three perspectives. In other words, network generation can be seen as increasing organisational adjustments, collaboration methods, and the perception of organisational involvement (Zancan, Santos \& Campos 2012).

This study focuses on collaboration methods by investigating social networks from the perspective of collaboration between the components of a bank branch, whose employees need to operate within a social networking environment to develop relationships with other employees, promote interdependence between their activities, and allow information to travel within the bank's various departments and sectors.

The objective of this study is to understand the relationships among the participants in the network, their communication, and their likely coordination in the search of organisational goals. 
The basic ideas of SNA, with the objective of understanding the researched context, provide a basis for some conclusions about how the information process operates in the studied environment and how the connections in the network contribute to knowledge management.

Hanneman and Riddle (2005) point out the basic elements used in the graphical representation of a network that is made up of nodes, or points, as shown in Table 1:

Table No. 1: Basic Elements of SNA

\begin{tabular}{|l|l|}
\hline Basic elements & Descriptions \\
\hline Actor or Node & $\begin{array}{l}\text { Each individual, sector, or department that interconnects to form the } \\
\text { network. }\end{array}$ \\
\hline Links & $\begin{array}{l}\text { Graphic representations of lines that connect the points (actors or } \\
\text { nodes). }\end{array}$ \\
\hline Size & $\begin{array}{l}\text { The number of connections between the actors in a network. } \\
\text { amount of connections between them. }\end{array}$ \\
\hline Centrality & $\begin{array}{l}\text { Number of connections that an actor has with other actors in a } \\
\text { network, considering only adjacent relationships. }\end{array}$ \\
\hline Closeness Centrality & $\begin{array}{l}\text { Proximity between the actors, measured as the sum of the geodesic } \\
\text { distances between all the actors. }\end{array}$ \\
\hline Geodesic Distance & $\begin{array}{l}\text { The number of ties or links that indicate the shortest way between a } \\
\text { pair of nodes. }\end{array}$ \\
\hline Betweenness & $\begin{array}{l}\text { Considers an actor as a way to reach others because the actor is part } \\
\text { of geodesic paths among other pairs. }\end{array}$ \\
\hline Centrality & $\begin{array}{l}\text { The number of existing connections divided by } \\
\text { possible connections. } \\
\text { bidirectional arrows }\end{array}$ \\
\hline which & $\begin{array}{l}\text { Groups of actors with closer and more cohesive relationships, in } \\
\text { connections, collaborating to allow for more efficient sharing. }\end{array}$ \\
\hline
\end{tabular}

Source: Adapted from Hanneman and Riddle (2005). 
SNA measures can be seen as instruments that support the analysis and interpretation of the links between network participants and can report of the composition of the network and the level of the relationships among its participants. Thus, a researcher can objectively verify the density within a research group, and the information collected is essential for the presentation of the results.

Nonaka and Takeuchi (2008) consider that information is processed in organisations and transformed into knowledge through interactions between the members of the organisation and the environment in which they operate. They also highlight the importance of the shared context in movement, as participants share information and create new ideas through interactions in the environment by exchanging knowledge either formally or informally.

In an analysis of social networks, Soares (2002) primarily considers the interdependencies among actors, where the links between them are the channels through which the flow of information passes and, even in groups, the individuals make their own decisions. He also states that network models are centred on individuals and conceptualises the structure as patterns of relationships among actors, and he observes that the network structure affects the actor's actions and perceptions of his own interest, showing that organisational behaviour can be influenced by the social network in which a collaborator participates.

\section{2 - INTRA-ORGANISATIONAL KNOWLEDGE}

SNA measures can be seen as instruments that support the analysis and interpretation of the links between network participants. They enable the measurement of the composition of the network and the level of relationships among its participants, which can objectively verify the density within a research group, in which the information collected, is essential for the results.

Because of their dynamics, networks work as spaces in which information and knowledge are shared within an organisational environment (Tomael, Alcará \& Di Chiara 2005).

According to Nonaka and Takeuchi (2008), explicit knowledge can be manifested in words, numbers, or sounds and divided into data, scientific formulas, visual aids, audiotapes, product 
specifications, or manuals. They further note that explicit knowledge can be rapidly transmitted to individuals in a formal and systematic way.

Conversely, tacit knowledge is too personal and too hard to formalise, inform, and divide given the heterogeneous nature of its formation, its experiential nature, and the influence of individual understanding on its accumulation. Nonaka and Takeuchi (2008) reinforce that knowledge is created and expanded through people's social connections when there is a connection between tacit and explicit knowledge. By this way of thinking, it is important to develop an environment that is conducive to the creation of ideas and information and, thus, the formation of knowledge, and the social connection processes from professional relationships help to form such an environment.

Grotto (2008) considers that the most important learning is among the individuals who belong to a group. Making tacit knowledge explicit is advocated by several authors, but this task is complex, as it requires observation, dialogue, and integration.

Stewart (1998) comments that locally networked companies create expressive ideas and knowledge cheaply, generating general savings and wealth in sharing learning.

In the view of Bryan, Matson, and Weiss (2007), companies need to build human and technological infrastructure, enabling the relationships generated through interorganisational networks.

Santos (2004, p. 55), when discussing competitive strategies and knowledge management, points out that 'the outcome of the set of changes aimed at strengthening the competitive position of organizations has resulted in new models and inter-organizational arrangements'. Knowledge emerges from multiple channels of information and relationships, often outside formal organograms. Properly integrating explicit and tacit knowledge, in the context of an organisation, seems to be the key to knowledge management. The great challenge for organisations is to create formal and informal mechanisms to promote the sharing of this knowledge in formal and informal networks.

The communication of people participating in the socialisation of learning shows social attributes, particularly regarding communities of practice. In this way, SNA allows us to 
understand how the participants who form networks relate and cooperate with each other to enable the exchange of knowledge (Farias, Farias \& Guimaraes 2010).

Cândido and Abreu (2000) argue that social networks, when applied to intra-organisational studies, cover internal aspects of the organisation, assuming that it can be viewed internally as a network of people, departments, and specific sectors. Thus, the organisation maintains a constant network of relationships, which is characterised by a hierarchical subdivision, the division of roles, and attributions of its components. Intra-organisational relationships are cutout in the study. Unlike interorganisational analyses, whose subjects are usually organisations, intra-organisational analyses focus on sectors and individuals, which are the 'nodes' of the network.

Organisations are located in social networks and are made of actors linked through specific social relationships. Thus, networks are socially constructed and are reproduced and modified over time as a result of the actors' interactions, which are influenced by the social structure (Nohria \& Eccles 1992).

Gulati (1998) proposes that the use of social networks also allows the relationships between the network elements to be considered in a larger structure in which goods and services, influence, and information are passed on. This method is an excellent alternative to integrate micro and macro perspectives.

\section{2- METHODOLOGY}

The study is carried out in a quantitative descriptive way, defining the participants of a social network and their possible relationships, considering that descriptive research makes it possible to describe the events of a given group. According to Gil (2010), this form of research facilitates descriptions of the attributes of individuals, organisations, and populations.

The goal of the research is to establish links between the employees of a large national bank branch. Thus, this study aims to determine what understanding the workers have of each other's work and, subsequently, how this understanding influences the activities in the branch. Thus, the intention is to highlight the various departments of this bank branch and the 
collaborations between the actors with the understanding that this information can provide actions for the planning and development of daily activities and in planning training events for the bank's employees.

To consolidate and interpret the data regarding the links between the actors, who are the nodes of the network, UCINET software, which is a tool for processing collected data and generating graphs and matrices, is used (Alejandro \& Norman 2005).

The network measures used in the study enable the description of the relational structures of each individual interviewed from the collected relational data. The measures chosen are the density, degree centrality, betweenness, eigenvectors, and cliques.

These approaches can represent the direct and indirect connections that occur between participants, links, and lines, with the goal of understanding the search for information among these participants using SNA. These relationships may present themselves in different ways in terms of their content, and there may be various structural particularities. The metrics used for this process are described in Table 2.

Table No. 2: Main Measures Applicable to SNA

\begin{tabular}{|l|l|}
\hline Measure & Description \\
\hline In-degree centrality & Sum of the connections entering a node. \\
\hline Out-degree centrality & Sum of the connections leaving a node \\
\hline Betweenness centrality & $\begin{array}{l}\text { Number of times a node appears as a path among all nodes } \\
\text { divided by the number of existing paths among all nodes. }\end{array}$ \\
\hline Closeness centrality & $\begin{array}{l}\text { Sum of the distance between a given node and all other nodes in } \\
\text { the network. }\end{array}$ \\
\hline Density & $\begin{array}{l}\text { Number of existing connections divided by the number of possible } \\
\text { connections. }\end{array}$ \\
\hline Reciprocity & $\begin{array}{l}\text { Number of bidirectional (reciprocal) connections divided by the } \\
\text { number of connections. }\end{array}$ \\
\hline Cohesion & $\begin{array}{l}\text { Number of bidirectional (reciprocal) connections divided by the } \\
\text { number of connections. }\end{array}$ \\
\hline
\end{tabular}

Source: Adapted from Hanneman and Riddle (2005).

Citation: VAILSON BATISTA DE FREITAS et al. Ijsrm.Human, 2020; Vol. 16 (1): 193-211. 
A self-completed questionnaire with closed-ended questions on a Likert scale was distributed to 35 employees of a bank branch located in the city of São Paulo (State of São Paulo, Brazil). The questions specifically dealt with the understanding of the activities performed by colleagues and the recognition of the importance of these activities for productivity among the employees. Thus, the survey asked: '1) what understanding do I have about the work performed by this person (...)', and the respondents provided a score from zero to ten regarding their degree of understanding about each colleague's work, where zero represents no understanding and ten represents the highest degree of understanding of the work done by the colleague. The respondents also indicated in the same questionnaire some predetermined attributes to help with the data analysis, such as their gender, work sector, function, time in their function, and total time with the bank. To process the data, each collaborator received an identification code according to their position to preserve their anonymity and facilitate the visualisation and analysis of the information. Thus, clerks are represented by 'CLE' and a randomly sequenced number (CLE1, CLE2, CLE3, etc.), and all other positions follow the same format, with the cashiers represented by CAS, the assistants represented by ASS, the assistant managers or supervisors represented by AMG, and the business managers or general managers represented by GMG.

The data is consolidated using the software UCINET 6.0 for Windows, a system prepared for the quantitative analysis of social networks. The NetDraw resource is used for graphic visualisation to demonstrate the network view (Hanneman \& Riddle 2005). In the data analysis, the links that originate the measures of centrality (i.e. in-degree and out-degree) in their dichotomised forms are considered.

\section{3- RESULTS AND DISCUSSION}

To answer the question 'what understanding do I have about the work done by this person?', we used the following NetDraw command to generate a sociogram, which is a network image in this case, to illustrate the interactions between members and their number of ties:

\section{FILE $>$ OPEN>UCINETdataSet $>$ NETWORK.}




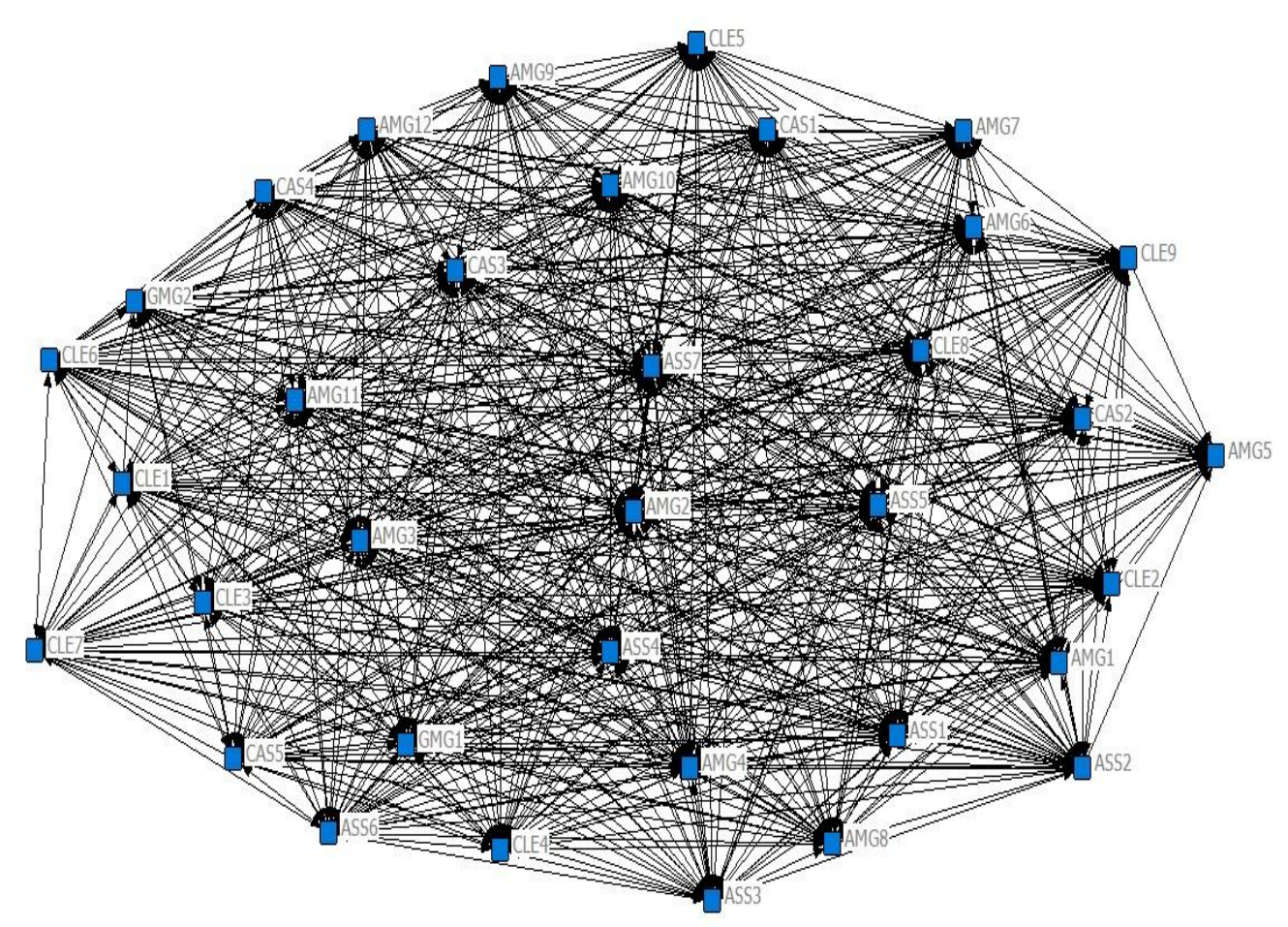

Figure No. 1: Outline of the network and its connections.

Source: Created by the authors, UCINET (2019).

The studied network contains 1118 connection links (Figure 1), where each link represents a connection between employees, defined in this case as the understanding that an employee has about the work of a colleague or colleagues. The degree of interaction can be observed in some cases, although there other cases in which there is no interaction; for example, the individuals CLE1, CLE4, and CAS1 have no understanding of the activities of other employees, which may mean, for example, that their relationships with their colleagues are not very interactive. The individuals with more interactions, that is, AMG9, AMG10, AMG11, GMG1, and GMG2, have leadership positions, indicating that because they deal with most of the individuals on a day-to-day basis, they have more understanding of their activities and are centralised in the network.

Degree centrality was calculated with the objective of observing the actors by their centrality degrees, where individuals, for example, were found to have many inputs (in-degree) and many outputs (out-degree), as shown in Table 3, which was obtained through the command NETWORK $>$ CENTRALITY $>$ DEGREE. Thus, the more that an employee understands the importance of a colleague's work, the more that colleague also understands the importance of the other's work. Just as the graphs illustrate, the data show that those who have greater 
degree centrality are mostly those who occupy management positions. Table 3 presents the data on out-degree and in-degree centrality for all the actors that compose the network and were questioned about their understanding of their colleagues' work. To make this table, the scores from zero to ten assigned according to the frequency of each relationship were considered, as were the number of relationships indicated for each actor. The scores were dichotomised to equal zero if the respondent did not understand and one if the respondent did understand the work of the colleague. For score from zero to five, the value 0 was assigned, and for score from six to ten, the value one was assigned.

Table No. 3- Degree Centrality of the Network.

\begin{tabular}{|c|c|c|c|c|c|c|c|c|c|c|}
\hline Number & Actor & $\begin{array}{l}\text { Out- } \\
\text { degree }\end{array}$ & \begin{tabular}{|l|}
$\begin{array}{l}\text { In- } \\
\text { degree }\end{array}$ \\
\end{tabular} & $\begin{array}{l}\text { Normalised } \\
\text { out-degree }\end{array}$ & $\begin{array}{l}\text { Normalised } \\
\text { in-degree }\end{array}$ & Gender & Function & Sector & \begin{tabular}{|l}
$\mathrm{T}$. \\
function
\end{tabular} & \begin{tabular}{|l|}
$\mathrm{T}$. \\
bank \\
\end{tabular} \\
\hline 1 & CLE1 & 0.000 & 22.000 & 0.000 & 0.647 & 2 & 1 & 2 & 2 & 2 \\
\hline 2 & AMG1 & 5.000 & 22.000 & 0.147 & 0.647 & 2 & 4 & 4 & 1 & 2 \\
\hline 3 & AMG2 & 25.000 & 21.000 & 0.735 & 0.618 & 1 & 4 & 4 & 2 & 3 \\
\hline 4 & ASS1 & 12.000 & 21.000 & 0.353 & 0.618 & 2 & 3 & 3 & 1 & 1 \\
\hline 5 & ASS2 & 29.000 & 22.000 & 0.853 & 0.647 & 2 & 3 & 4 & 2 & 3 \\
\hline 6 & CLE2 & 7.000 & 20.000 & 0.206 & 0.588 & 2 & 1 & 2 & 4 & 4 \\
\hline 7 & AMG3 & 24.000 & 25.000 & 0.706 & 0.735 & 1 & 4 & 3 & 2 & 3 \\
\hline 8 & ASS3 & 21.000 & 20.000 & 0.618 & 0.588 & 2 & 3 & 4 & 2 & 2 \\
\hline 9 & ASS4 & 23.000 & 22.000 & 0.676 & 0.647 & 2 & 3 & 4 & 2 & 2 \\
\hline 10 & CLE3 & 33.000 & 19.000 & 0.971 & 0.559 & 1 & 1 & 4 & 1 & 4 \\
\hline 11 & CLE4 & 0.000 & 23.000 & 0.000 & 0.676 & 2 & 1 & 2 & 2 & 2 \\
\hline 12 & GMG1 & 29.000 & 25.000 & 0.853 & 0.735 & 2 & 5 & 5 & 2 & 4 \\
\hline 13 & ASS5 & 34.000 & 23.000 & 1.000 & 0.676 & 1 & 3 & 4 & 1 & 4 \\
\hline 14 & CLE5 & 21.000 & 20.000 & 0.618 & 0.588 & 1 & 1 & 2 & 1 & 1 \\
\hline 15 & AMG4 & 30.000 & 25.000 & 0.882 & 0.735 & 1 & 4 & 2 & 2 & 3 \\
\hline 16 & AMG5 & 15.000 & 20.000 & 0.441 & 0.588 & 2 & 4 & 3 & 2 & 3 \\
\hline 17 & ASS6 & 34.000 & 16.000 & 1.000 & 0.471 & 2 & 3 & 4 & 1 & 1 \\
\hline 18 & CLE6 & 14.000 & 17.000 & 0.412 & 0.500 & 1 & 1 & 2 & 2 & 2 \\
\hline 19 & CLE7 & 2.000 & 18.000 & 0.059 & 0.529 & 2 & 1 & 2 & 3 & 3 \\
\hline 20 & AMG6 & 18.000 & 22.000 & 0.529 & 0.647 & 1 & 4 & 3 & 1 & 3 \\
\hline 21 & AMG7 & 25.000 & 23.000 & 0.735 & 0.676 & 1 & 4 & 3 & 1 & 2 \\
\hline 22 & CLE8 & \begin{tabular}{|l|}
16.000 \\
\end{tabular} & 21.000 & 0.471 & 0.618 & 1 & 1 & 1 & 2 & 4 \\
\hline 23 & GMG2 & 33.000 & 26.000 & 0.971 & 0.765 & 1 & 5 & 5 & 4 & 4 \\
\hline 24 & CLE9 & 9.000 & 17.000 & 0.265 & 0.500 & 2 & 1 & 2 & 3 & 3 \\
\hline 25 & AMG8 & 18.000 & 22.000 & 0.529 & 0.647 & 1 & 4 & 4 & 1 & 3 \\
\hline 26 & AMG9 & 33.000 & 25.000 & 0.971 & 0.735 & 1 & 4 & 2 & 2 & 2 \\
\hline 27 & AMG10 & 33.000 & 24.000 & 0.971 & 0.706 & 1 & 4 & 4 & 2 & 3 \\
\hline 28 & AMG11 & 30.000 & 23.000 & 0.882 & 0.676 & 1 & 4 & 1 & 2 & 4 \\
\hline 29 & ASS7 & 34.000 & 22.000 & 1.000 & 0.647 & 1 & 3 & 3 & 1 & 3 \\
\hline 30 & CAS1 & 4.000 & 17.000 & 0.118 & 0.500 & 2 & 2 & 6 & 4 & 4 \\
\hline
\end{tabular}




\begin{tabular}{|l|l|l|l|l|l|l|l|l|l|l|}
31 & CAS2 & 30.000 & 21.000 & 0.882 & 0.618 & 2 & 2 & 6 & 2 & 3 \\
\hline 32 & CAS3 & 33.000 & 21.000 & 0.971 & 0.618 & 1 & 2 & 6 & 2 & 3 \\
\hline 33 & AMG12 & 19.000 & 21.000 & 0.559 & 0.618 & 1 & 4 & 6 & 2 & 4 \\
\hline 34 & CAS4 & 32.000 & 19.000 & 0.941 & 0.559 & 2 & 2 & 6 & 4 & 4 \\
\hline 35 & CAS5 & 19.000 & 19.000 & 0.559 & 0.559 & 2 & 2 & 6 & 3 & 3 \\
\hline
\end{tabular}

Source: Prepared by the authors. Caption: Gender 1 - male; 2 - female. Work Sector: 1 - preservice; 2 - retail; 3 - natural person; 4 - legal person; 5 - branch administration; 6 operational service platform. Time in the function and in the bank: 1 - zero to two years; 2 three to five years; 3 - six to ten years; 4 - over 11 years.

The centrality degree and the power command, given by NETWORK>CENTRALITY >POWER, examine the centrality and the power scores for our information exchange data. We calculate Bonacich measures of power and verify that the actor GMG2 has the greatest power of interaction with colleagues, followed by the other managers. Thus, we can see that those who have some formal power within the institution seem to also understand the importance of the work of their colleagues the best.

Closeness centrality, where the 'closeness' of each actor is calculated in relation to the others, shows the geodesic distances among the actors. This calculation is performed using the command NETWORK>CENTRALITY $>$ CLOSENESS, and we verify that CAS1 and ASS6 have the greatest geodesic distances in their relationships. Thus, they have more capacity to connect with the rest of the actors of the network. Conversely, the actors CLE4 and CLE1 have the smallest proximity, showing that they are not well positioned within the network. The statistical analysis shows a standard deviation of $4.72 \%$ between the relationship lines.

The measure of closeness called reach centrality aims to verify the distance between the actors and the number of steps that it takes to reach the others. It is calculated through the command NETWORK>CENTRALITY>REACHCENTRALITY. This analysis shows which actors have to move less to reach the other members of the network. In this case, these actors are actors 17,29 , and 13, considering the number of nodes that they have. In contrast, the actors who have to move more if they wanted to relate to and understand the activities of the others in the network are actors $19,1,1$ and 01. 
The command UCINET NETWORK>CENTRALITY>EIGENVECTOR is used to calculate the centrality of each of the actors in the network and also to graphically centralise them using the weights of the first eigenvector that calculates the centrality of each actor. The first factor has a percentage of $66.4 \%$, showing that more than half of the distances between the actors reflect a pattern of behaviour in terms of understanding of the activities performed by their colleagues. The actors ASS5, AMG4, ASS6, and ASS7 are the most central, as they have the highest indices, including equal relationships, indicating their degree of power within the network. The actors CAS1, CLE7, CLE9, and CLE1 have the lowest indices, indicating that they are on the edge of the network with little ability to understand others' activities. In the general verification of the graph and the distribution of the centralities, we calculate a standard deviation of 0.02 around the mean of 0.17 , suggesting that the centralities or powers of the actor do not differ greatly. The degree of concentration of Knoke data is only $5.35 \%$ of the maximum possible, showing that the network interactions can increase.

When analysing closeness through the measures of influence and information with the NETWORK>CENTRALITY >INFORMATION command, it is possible to verify in the network that the actors AMG11, ASS2, and AMG7 are those with the greatest influence and information capacity in the network, but it is necessary to observe that two of these actors have management positions, which may help them. Additionally, the actors CAS1, CLE7, and CLE9 have less influence and information capacity within the network.

The Betweenness centrality analysis using the command NETWORK>CENTRALITY>FREEMANBETWEENESS $>$ NODEBETWEENESS

verifies that the actors in the network may have interdependencies with the others, regardless of whether they have favourable situations in the network, to enable communication with actors with whom they do not yet communicate. To efficiently initiate a communication process, it is sometimes necessary to have an intermediary. We verify that the actors CLE3, GM5, GMG2, GMG1, and AMG10 have the greatest potential to relate to others within the network, given their large numbers of connections and the fact that they clearly stand out from the others. Conversely, the actors ES4, CAS1, and CLE1 are completely neutralised given the fact that they do not have connections and are even outside the graph. This measure greatly varies among the actors, ranging from 0 to 29 , with a variance of $59 \%$ and a standard deviation of 7.72 with a mean of 10 , demonstrating that the network has a very low 
centralisation on the order of $1.8 \%$. Thus, the actors have the freedom to communicate with each other.

The analysis of the network's attributes in Figure 2 shows the existence of 175 relationship ties and 41 nodes among network members according to the attributes of sector, time in the bank, gender, function, and time in the function. The actors with the most ties are GMG2, CAS2, CAS4, and CAS5, confirming that having a leadership position or remaining in a certain function for a long time implies in this case that an actor has a greater understanding of the activities performed in other sectors.

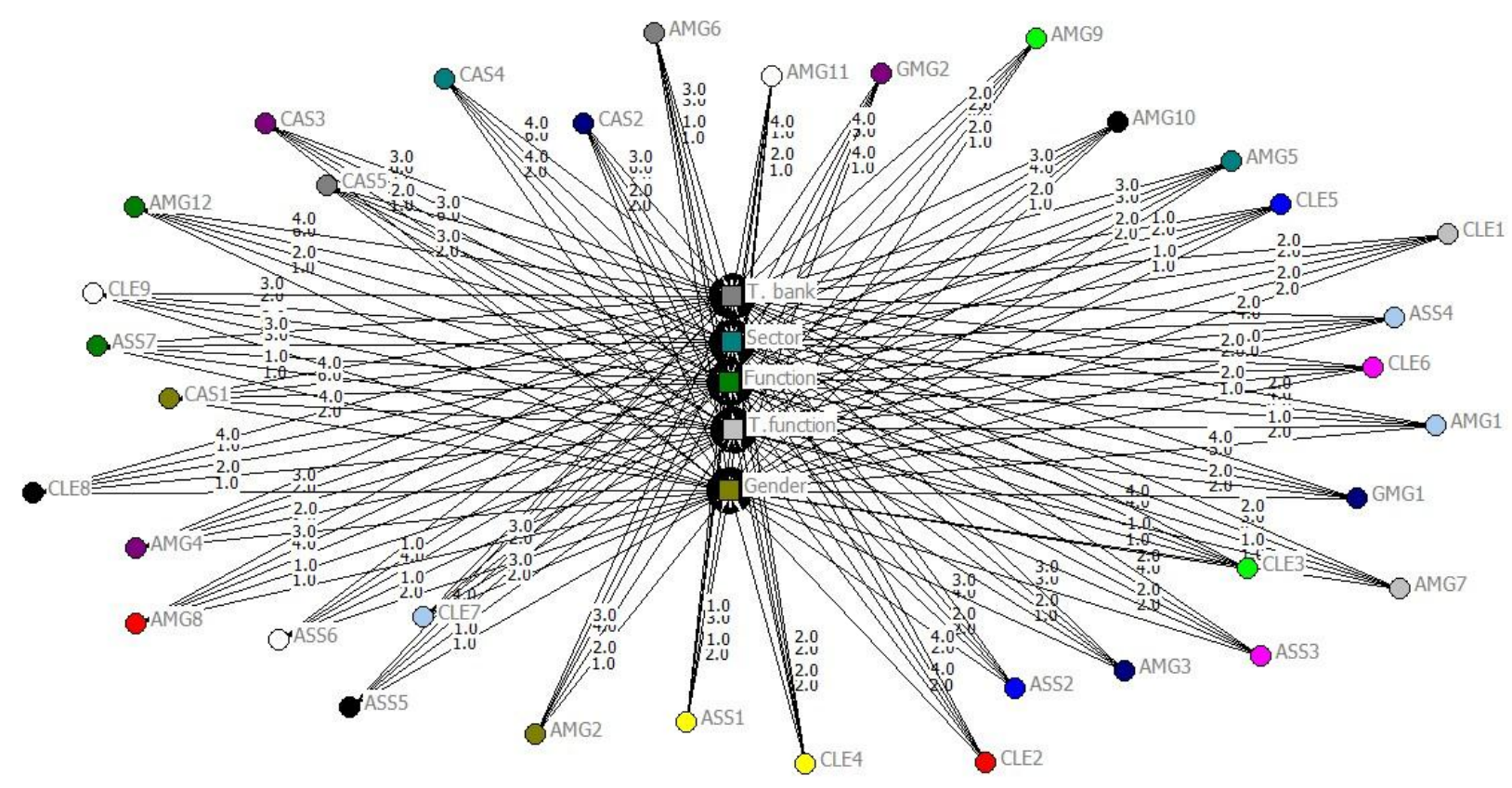

Figure No. 2- Attributes of the network - ties and nodes.

Source: Created by the authors, UCINET (2019).

\section{4- FINAL CONSIDERATIONS}

This study aimed to confirm the premise that the workers at a bank branch understand the importance of the work performed by their colleagues and that this understanding is an essential mechanism for sharing and generating knowledge through socialisation and making 
tacit knowledge explicit. In this context, we then sought to verify how this understanding occurs within the work environment involving all hierarchical levels of the branch.

The results allow us to conclude that, for the group studied, there is a certain degree of interaction for which most of the actors understand the activities performed by their colleagues. Thus, we can conclude that this understanding leads to the creation of ties that help in the learning of new activities and finding eventual solutions to problems that arise in the execution of daily activities.

We verified within the group that employees who remain in a certain position or function for a longer time have a greater understanding of other activities and that employees who occupy higher hierarchical positions are more important because they are involved with all other activities on a greater or lesser scale. Thus, they have a greater understanding of these activities. The attributes 'time of work in the institution' and 'time in the function' are factors that deserve to be highlighted in the study because these attributes influence the interaction between the actors in the sense that the time spent working in an institution or sector influences the established ties and the perception of others regarding the understanding of the importance of the activities performed in that institution.

Finally, other studies analysing social and intrapersonal networks and their influence on the performance of teams and organisations are suggested to expand the discussion of this premise of understanding to other business segments, including comparisons between different networks.

\section{COMPETING INTERESTS}

The authors declare that they have no financial or personal relationships that may have inappropriately influenced the authors when writing this article.

\section{AUTHOR CONTRIBUTIONS}

All authors meet the criteria for authorship described in the authoring policies and declaration policies of the author's contribution, aiming at a better dissemination of scientific research in administration. 


\section{www.ijsrm.humanjournals.com}

\section{Data availability}

The data that generated the results of this research are available for consultation with the authors.

\section{Disclaimer}

The opinions expressed in this article are those of the authors and do not reflect any opinions of the Institutions mentioned.

\section{ACKNOWLEDGMENT}

We thank the Federal Institute of Education Science and Technology Goiano - IF Goiano, for encouraging the qualification it offers to its servers.

\section{5- REFERENCES}

1. Ahuja, G., 2000, 'Collaboration networks, structural holes, and innovation: a longitudinal study', Administrative Science Quarterly 45(3), 425-455.

2. Alejandro, V. A. \& Norman, A.G., 2005, 'Introductory manual to social network analysis', in Measures of Centrality, from http://www2.unicentro.br/lmqqa/fi les/2016/05/Manualintrodutorio_ex_ucinet.pdf. Accessed on $06 / 06 / 2020$

3. Borgatti, S.P., 2002, NetDraw network visualization, Analytic Technologies, Harvard, MA.

4. Bryan, L.L., Matson, E. \& Weiss, L.M., 2007, 'Harnessing the power of informal employee networks'. Electric Perspectives. Nov-Dec., Edison Electric Institute Inc.

5. Cândido, G.A. \& Abreu, A.F., 2000, 'The concepts of networks and interorganizational relations', an exploratory study in: Anais do XXIV Enanpad, ANPAD, Florianópolis.

6. Castells, M., 2008, 'The network society'. São Paulo: Peace and Earth, 1999. Nova Economia, Belo Horizonte, MG, 18(1), 11-32.

7.Farias, J.S., De Farias, M.N. \& De Aquino G.T., 2010, 'Sociometric analysis of a knowledge transfer network'. Revista de Administração FACES Journal 9(1), 11-31.

8. Farina, M.C., 2014, 'Analysis of social network', in E.E. Goulart (ed.). Social media: a contribution of analysis, EDIPUCRS, Porto Alegre, RS.

9. Freeman, L.C., 1979, 'Centrality in social networks: Conceptual clarification'. Social Networks 1, $215-239$.

10. Gil, A.C., 2010, How to elaborate research projects, 5th ed., Atlas, São Paulo.

11. Grotto, D.O., 2008, 'The sharing of knowledge in organizations', in Knowledge organizations: Infrastructure, people and technology, 2nd ed., Saraiva, São Paulo.

12. Gulati, R., 1998, 'Does familiarity breed trust? The implications of repeated ties for contractual choice in alliances', Strategic Management Journal 19, 293-317.

13. Hanneman, R.A., 2001, Introduction to social network methods, University of California, Riverside, CA.

14. Hanneman, R.A. \& Riddle, M., 2005, Introduction to social network methods, University of California, Riverside, CA.

15. Latour, B., 2001, Science in action: how to follow scientists and engineers throughout society. 2nd ed., transl. I.C. Benedetti, Editora Unesp. São Paulo. 


\section{www.ijsrm.humanjournals.com}

16. Marques, E.C., 2006, 'Social networks and power in the Brazilian State: learning from urban policies', RBCS 1(60), 15-41.

17. Marteleto, R.M., 2001, 'Analysis of social networks - application in information transfer studies', Revista Ciência da Informação, Brasília 30(1), 71-81.

18. Nelson, R., 1984, 'The use of social network analysis in the study of organizational structures', Revista de Administração de Empresas, São Paulo 24(4), 150-157.

19. Nonaka, Takeuchi, H., 2008, Knowledge management, Bookman, São Paulo \& I.

20. Nohria, N. \& Eccles, R.G., 1992, Networks and organizations: structure, form, and action, Harvard Business School Press, Boston, MA.

21. Pinto, A.M.G. \& Junqueira, L.A.P., 2009, 'Power relations in a third sector network: a case study', Revista de Administração Pública 43(5), 1091-1116.

22. Rossoni, L, Ferreira Júnior, I. \& Hocayen-Da-Silva, A.J., 2006, 'Administração de ciência e tecnologia: a produção científica brasileira entre 2000 e 2005'. In Symposium of Technological Innovation Management, 24, ANAPD, Gramado.

23. Scott, J., 2000, Social network analysis: a handbook, 2nd ed., Sage Publications Ltd., London.

24. Stewart, T.A., 1998, Capital Intellectual, Elsevier, Rio de Janeiro.

25. Silva, A.B.D., Matheus, R.F., Parreiras, F.S. \& Parreiras, T.A.S., 2006, 'Study of the network of coauthorship and interdisciplinarity in scientific production based on the methods of analysis of social networks: evaluation of the case of the postgraduate program in information science - PPGCI/UFMG', Encontros Bibliticos: Revista Eletrônica Biblioteconomia e Ciência da Informação, Florianópolis special issue, 179-194.

26. Soares, W., 2002, 'Beyond the metaphorical conception of social networks: theoretical foundations of the topological circumscription of international migration', in Meeting of the Brazilian association of populational studies, Nov., Ouro Preto, Minas Gerais. Annals... UFMG/Cedeplar.

27. Tomael, M.I. \& Marteleto, R.M., 2006, 'Social networks: positions of the actors in the flow of information', Bibliographic Meetings: Electronic Magazine of Librarianship and Information Science, Florianópolis, SC special issue, 75-91.

28. Tomael, M.I., Alcará, A.R. \& Chiara, I.G., 2005, ‘From social networks to innovation', Information Science 34(2), 93-104.

29. Wasserman, S. \& Faust, K., 1994, Social network analysis: methods and application, Cambridge University Press, Cambridge.

30. Watts, D.J., 1999, Small worlds: the dynamics of networks between order and randomness, Princeton University Press, Princeton, NJ.

31. Zancan, C., Santos, P.D.F. \& Campos, V.O., 2012, 'The theoretical contributions of social network analysis (ARS) to organizational studies', Revista Alcance, Biguaçu, SC 19(1), 62-82. 